\title{
Observing the Job Satisfaction of Employees of SGS Automotive Albania
}

\author{
Prof. As. Dr. Gaqo Tanku \\ Dr. Piro Tanku
}

Doi:10.5901/mjss.2015.v6n6s4p69

\section{Abstract}

The object of this study is company SGS (Societe Generale Surveillance) Automotive Albania, the Swiss company the world's leading inspection, verification, testing and certification. The company has 31 lines and certifies vehicle technical control throughout the Republic of Albania. Specialized staff consists of a staff of more than 120 people. The purpose of this paper is the identification of factors that influence the level of satisfaction / dissatisfaction of the employees. Paper target group are employees of SGS (30 employees) at various functions. To measure the degree of job satisfaction were used two indicators known to express their level of satisfaction: the first is the index of job description, which measures five aspects of job satisfaction: 1-Work 2-Supervisor, 3 People 4-Money and 5-Promotion. The points system is available to ensure the satisfaction index. Another indicator is the satisfaction questionnaire Minnesota. They were asked to answer employees' satisfaction in their work through Likert scale from one to five which included: 1. Decision-making Skills Supervisor, 2-Working Possibilities for long-term, 3-Work conditions, etc. The results showed that employees were satisfied generally level on average, based on the factors determining job satisfaction.

Keywords: motivation, job satisfaction, management, supervisor, salary.

\section{Introduction}

Job Satisfaction is a new concept that is used in our organizations, while demand is growing in society. Measuring job satisfaction serves as an important factor in pushing ahead of it. Managers now have become aware that employee job satisfaction increases work efficiency and thus the performance of the company.

Level of satisfaction from work affects the results of the work, the number of absences at work and motivation of employees. Otherwise they will be removed by creating costs for the company, for the recruitment and training of new employees, etc. Studies show that happy employees are productive, provide high quality service to customers. Organizations need to absorb and recruit good employees with talent, motivating financially, created better working conditions, opportunities for achievement and career. These will make possible the holding of the best employees of the talented.

This paper will focus on the measures undertaken to make employees more satisfied.

\section{Methodology}

To make the proper analysis is used in the literature references and data collection in the field. It surveyed 30 employees from 120 to the organization (25\% of all employees). The respondents were employees in different positions namely 3 managers, 2 sanitary 3 receptionist, 1 worker's office and 21 other reservations with the task Inspector.

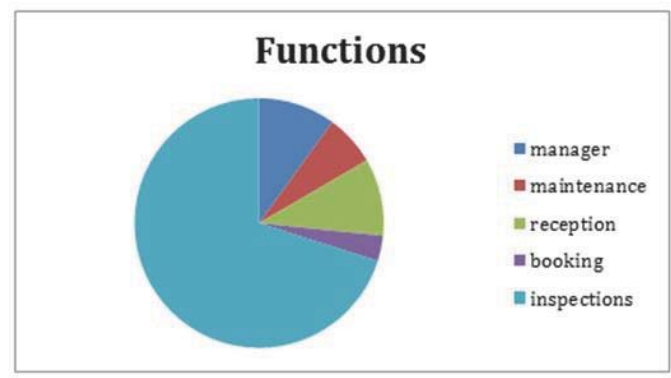

Figure 1. Age of personnel involved in the study 
Worker involved in this work by age represented graphically as follows:

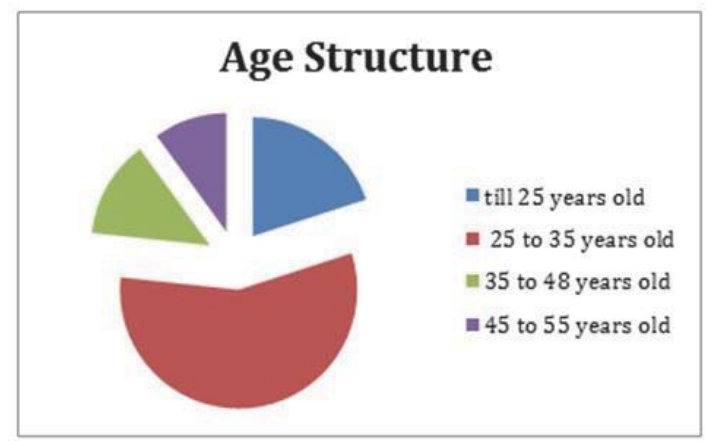

Figure 2. Graphical display restraint

\section{Review of the Literature}

\subsection{Concepts job satisfaction}

Job Satisfaction refers attitudes of people in relation to the work they do. (Gary Johns, Alan M.Saks, 111:2005).

"The degree of job satisfaction is important for individuals" and the desire for pleasant conditions and effective at work is the desire for personal sufficiency and to earn the respect of the others (Robert N.Lussier and John R.Hendon. 363:1996)

Job satisfaction is the amount of pleasure associated with work and from the perception that the work of an employee gives or provides him / her, for what he / she considers as important in a job. (Mimoza Manxhari 190:2013)

Job satisfaction is depending on a number of factors starting from starting work, its conditions, and to what an individual experiences when performing that job. As said, "in general I really enjoy my work, although some aspects of it must be improved, it is an indicative of general satisfaction" (. Gary Johns, Alan M. Saks 111:2005).

Overall satisfaction is an average or the sum of individual attitudes that are held on various aspects of the work. The level of satisfaction may be different from one employee to another, based on the perception of the above factors, while there are various estimates within the same organization in relation to job satisfaction.

\subsection{Theoretical aspects of job satisfaction}

\subsubsection{Theory mismatch job satisfaction}

This theory maintains that satisfaction is a function of the discrepancy between the results that people want from their work with the results that will perceive that. In general, employees of whom most aspects of the work, complies with the wishes they have, receive the greatest pleasure.

\subsubsection{Theory Supplement}

According to this theory, pleasure to work will depend directly by the masses of meeting the needs that individual wanted to complete. (Mimoza Manxhari 190:2013). The researchers advocate that people's satisfaction is a function of two factors:

a. the quantities they receive

b. quantity that feels need or want to make.

\subsubsection{Theory of impartiality}

Inputs that people perceive as investment in work and productivity that provide it, despite inputs and products compare to some other person or group of those similar to them. 


\section{Products that are received $=$ Products of others}

Inputs to invest inputs that invest others

Any individual under this theory, judges for compensation related to input as work areas of experience, hours of work, performance at work, but compared to the rewards that are given to others working in the same organization. So according to this theory, distributed impartially job performance contributes to the pleasure we have at job place. (Griffin and Moorled. 102:2014)

\subsubsection{Hierarchy Needs Theory}

With representatives like Maslow it is assumed that within every human being there is an extremely powerful number of needs that are positioned against each other in a hierarchy that are physiological needs, for security, connectivity, and self-actualization. (Griffin and Moorled. 93:2014). This theory sees job satisfaction as a result of meeting the needs of people. That should be met the needs of the first level, and then the second level, and so on.

\subsubsection{The theory of dual factors or hygiene-motivation}

With representatives like Herzberg, who concluded that the opposite of satisfaction is not dissatisfaction and the removal of the negative characteristics of a job does not make him necessarily satisfactory, but affects the discontent. The other conclusion is that even if Herzberg factors that bring pleasure are lacking, this does not necessarily lead to dissatisfaction, but will decrease the level of satisfaction. Factors that lead to dissatisfaction at work are separate and different from those that lead to dissatisfaction. Features such as Company policy, administration, supervision, working conditions, wages, relations between people are considered as factors of hygiene, which emanate from the nature of the exterior work, while the factors that bring satisfaction (motivators), including the possibilities and walking career, gratitude, work itself, responsibility. These factors derived from the intrinsic nature of work (Griffin and Moorled. 93:2014).

\subsection{Factors related to job satisfaction}

Various scholars have concluded that the salary is the main demand of the employees who seeks employment, while special factors perceived in different ways including the impact on their work. When employees are dissatisfied, they lack work, exhibit fatigue, show low interest or can be removed entirely from work.

\subsection{The consequences of job satisfaction}

Leaving work: The relationship between satisfaction and dismissal are disproportionately. The greater satisfaction at work, the more reduced the possibility of dismissal.

Absences: so was the relationship between the lack of job satisfaction. How much less / pleased to be working so little we lack.

Health: Studies show that physical and mental health is qualitatively higher off to a satisfactory environment. Life is expected to be longer for employees satisfied. Less anxiety and tension employee noticed satisfied.

Productivity, has long been defending the idea that an individual is happy Satisfied and productive (M.Manxhari, ibid).

\section{Analysis of Data}

The questionnaire Index use of job description (the work itself, pay, supervisor, colleagues, promotion) and that Minnesota questioner was used to conduct the study. Likert scale responses were reflected by the following:

\subsection{The work itself}

$66 \%$ of employees expressed that their work was routine.

$11 \%$ were not at all agreeing that their work was routine.

$23 \%$ were moderately agreed that their work was routine.

$3.3 \%$ said that their work was creative.

$96.7 \%$ disagreed that their work was creative.

$27 \%$ agreed that their work gives meaning achievements. 
$73 \%$ disagreed with their achievements in the workplace.

Conclusion: The data show that the work itself as a contributing factor in job satisfaction, is routine and noncreative process. In most cases it is stressful and overloaded. Most employees of viewing daily work process as needed to fulfill the needs of low-level (Maslow Theory) than achieving fulfillment of high-level needs.

\subsection{Supervisor}

$50 \%$ of respondents stated that required supervisor advice from employees or their suggestions into consideration.

$16.6 \%$ said they generally took their suggestions into consideration.

$33.3 \%$ stated that the manager did not require advice and does not take into consideration their suggestions.

$26.6 \%$ noted that receive no thanks from their supervisor.

$46.6 \%$ said they receive thanks.

$23.3 \%$ said they generally receive thanks.

$33.3 \%$ stated that the supervisor exercise more control over the entire work process.

$66.7 \%$ said they did not control supervisor more.

Conclusion: In connection with Supervisor turns a generally satisfactory relationship of employees, a fruitful collaboration between colleagues. She/he exercised process control fairly and impartially, without creating stress (of course for employees to strictly honor the Integrity Code). Working as a team are also face difficult situations, especially in the period of the season where even more load.

\subsection{Colleagues (People)}

$63.4 \%$ of respondents said they do not speak their colleagues more

$20 \%$ agreed that their colleagues speak more

They averaged $16.6 \%$ agree that their colleagues talk more.

$65.4 \%$ were fully agree that the relationship with colleagues was very important and the most important factor to achieve job satisfaction.

$34.6 \%$ were moderately agreed.

$70 \%$ said they had fruitful cooperation with colleagues.

$23.4 \%$ said that the cooperation was in the average.

$6.6 \%$ said that their colleagues were not cooperative.

Conclusion: The data of the respondents state that their colleagues do not talk much, that we respect the Code of Integrity, which prohibits rumors, slander, and disinformation. In this regard they expressed satisfaction with their colleagues. Furthermore, stress that they consider the most important factor, which contributes to job satisfaction, in good relations with co-workers, including situations of ongoing collaborative process workday.

\subsection{Salary}

$76.6 \%$ of respondents stated that paid well and that the amount was the primary factor of job satisfaction.

$13.4 \%$ to be paid very well.

$10 \%$ paid less and are dissatisfied with the salary.

$80 \%$ paid on merit and are satisfied with the salary they receive.

$20 \%$ of respondents said they paid less than they deserve.

Conclusion: the respondents stated that we are generally satisfied with wages, since it is the most important motivator of their work.

\subsection{Promotion}

$16.6 \%$ stated that they were in favor of policies that were followed for promotions and see the opportunity to make a career in the company.

$63.3 \%$ disagreed with the policies being followed that career is something difficult to achieve.

$20 \%$ felt that career opportunities in companies are 50\% / 50\%.

$20 \%$ said they work to promote career according to their abilities.

73.3\% gave an answer that promotion, functioning not based on skills. 
$6.7 \%$ believe that the promotion works based on the skills of employees, but the report $50 \%$ / $50 \%$.

$90 \%$ of respondents do not see transparent promotion policy, while 10\% stated that policies for promotion were transparent.

Conclusion: The employees do not see the opportunity to make a career, it is difficult and are skeptical about this fact. Some think that can be promoted, but this number is in a small extent. Other employees (50\% / 50\%) find it difficult walking career opportunity. Promotion policies were not transparent in most of the answers.

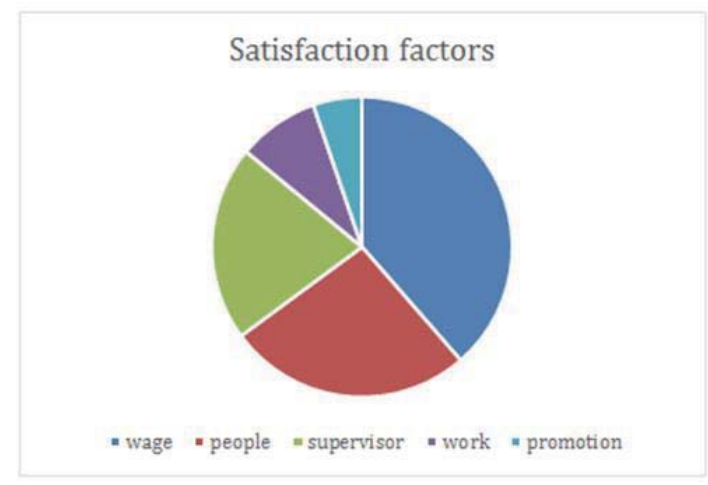

Figure 3. Ranking of factors of satisfaction according to the respondents' opinions.

Regarding the survey by questionnaire Minnesota, we focused on three elements (decision-making, resistivity and working conditions). In the process of decision-making, $80 \%$ of respondents stated that they almost never included in the process.

$13.3 \%$ said they are somewhat involved in decision-making, while $6.6 \%$ of them stated that included in decisionmaking.

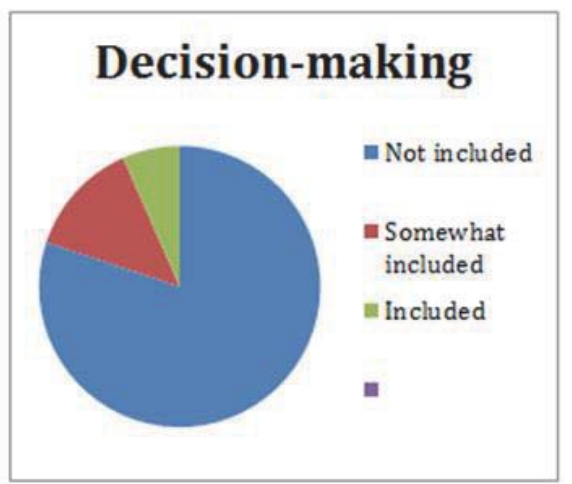

Figure 4. Employee involvement in decision-making by

Sustainability at work. This is an interesting factor for our reality and in this case $73.3 \%$ expressed that opportunities to stay longer are slim, while 10\% said that there are opportunities for long-term stays.

$16.6 \%$ expressed that the possibility of long-term sustainability in business is in the range $50 \%$ to $50 \%$. 


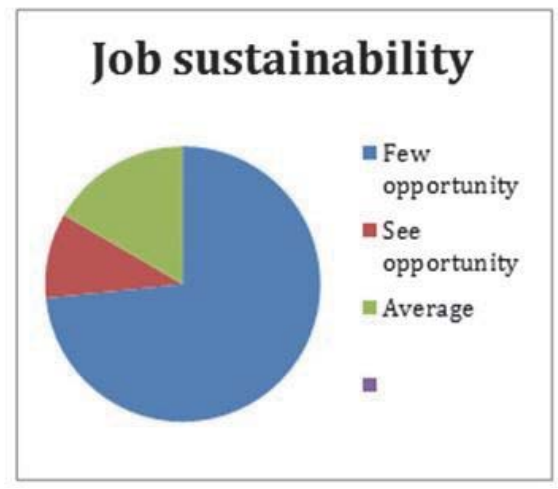

Figure 5. Opinions regarding sustainability at work conditions

$50 \%$ of respondents stated that they are satisfied with the working conditions offered, while $20 \%$ stated that they are dissatisfied.

$30 \%$ were moderately satisfied with the agreement or working conditions.

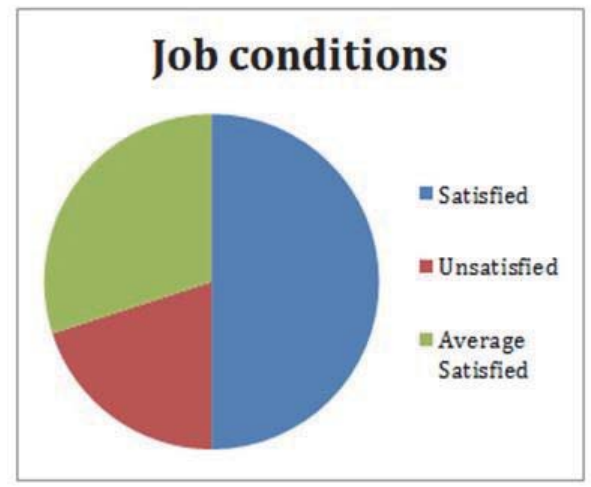

Figure 6. Opinions of the employees related to working conditions.

\section{Recommendations}

1) With respect to working factor that contributes to employee satisfaction, the company deems that it should support more staff, especially for coping with stressful situations. Special assistance be provided to meet the challenges that appear every day in the work process. In the case of overload at work, the companies to increase even more care to workers and strengthen control in order to be continuity in the relationship worker client, especially in the reduction of stressful situations. A satisfied employee offers quality service.

2) Regarding the Supervisor-company think it should focus more on the process of decision making, coping with unexpected situations that may occur or have occurred, such as defects in software, control lines, staff shortages, we full compliance with the realization of the objectives of the company.

3) We think about staffing company to plan more frequent training on performance (Code of Integrity), stop all degrading situations to work colleagues. Integrity Code of the Company that: - do you tell a colleague that you will not want to make other, to be in the spotlight and open communication method to be implemented widely. Many transfers of employees, particularly horizontal, do not become known, but movements are performed today for tomorrow, the man on the other Albania. These do not bear in mind the family problems that may have employees, (single family, small children, etc.). These remissions affect largely in resentment and stress. 
4) Our suggestion for the company is that it should distribute rewards fairly and fair by rewarding each employee based on performance and skills. Occasionally they are revised salaries for employees who deserve more, including the bonuses as part of remuneration for the staff better.

5) The administrator of the company to understand and act better in the role of a leader as well as the manager, avoiding conflict of roles, so that company policies give employees opportunities for career promotion. Promotion to function based on the skills of the Code of Integrity. Promotion policies take place transparence for all employees including the selection, recruitment, retention and performance based assessment.

6) The company think that should execute good open communication manager - employees. Staff included in the decision-making process, for further serves the process of achieving the objectives of the company.

7) Regarding the sustainability work, which for the sake of truth few employees viewing opportunities, the company will make more efforts in matters of safety at work, to increase confidence through training employees, increasing the opportunities for long-term approach to work respecting the Code of Integrity of the company, through the implementation of which could become a career, as happens in SGS around the world. So, to work with the staff that SGS has the same standards as in Albania, as well as in Switzerland and in any other country of the world where SGS operates. SGS is known as one of the leading companies that provide standards and safety at work. The same concept exists and for SGS in Albania.

8) Regarding working conditions, the company needs do more to improve there the quality of life at work, because self-service environment where the focus of the company is the highest polluted vehicles of hydrocarbons. It needs be provided with modern facilities and more control lines, providing greater space and why not and green.

\section{References}

(Gary Johns, Alan M.Saks, Organization Behavior. Sixth Edition. Understanding and Managing Life at work.pg.111, 2005. Pearson Education Canada, Inc.Toronto Canada).

(HRM, Second Edition. Robert N.Lussier and John R.Hendon. 1996. pg.363)

(Mimoza Manxhari "bring to the organization." Understanding and managing the organization's human terms, Tirana, 2013, pg.190)

(. Gary Johns, Alan M.Saks, Organization Behavior. Sixth Edition. Understanding and Managing Life at work.pg.111, 2005. Pearson Education Canada, Inc.Toronto Canada).

(Organizational Behavior, Managing People and Organization. Pg.102. Griffin and Moorled. 2014)

((Organizational Behavior, Managing People and Organization. Pg.93. Griffin and Moorled. 2014).

(Organizational Behavior, Managing People and Organization. Pg.93. Griffin and Moorled. 2014). 